\title{
Retroactive interference from translation equivalents: Implications for first language forgetting
}

\author{
LUDMILA ISURIN and JANET L. MCDONALD \\ Louisiana State University, Baton Rouge, Louisiana
}

\begin{abstract}
First language vocabulary is vulnerable to forgetting after massive exposure to a second language. Two possible factors responsible for the forgetting are degree of semantic overlap between concepts in the two languages and amount of second language exposure. In a laboratory simulation of the language forgetting situation, participants received 10 exposures to a list of words in a foreign language, followed by $2,5,10$, or 15 exposures to a list in a second foreign language. The second list consisted of either translation equivalents or new concepts. Participants were then tested for retention of the first list. More retroactive interference was found for translation equivalents than for new concepts and for higher degrees of exposure to the second list. When retention of the first list was broken down in terms of gains and losses, effects of both similarity of the second list to the first and amount of exposure to the second list were found only for losses-a fact that points to lack of discriminability as one of the underlying causes of forgetting. Overall, the experimental paradigm proved useful for exploring and developing theories about the causes of first language forgetting.
\end{abstract}

The field of study known variously as first language forgetting, first language loss, or first language attrition (de Bot, 1999; Pan \& Gleason, 1986; Seliger \& Vago, 1991) has seen a surge of interest in the past decade. This field examines the forgetting of first language (L1) skills as second language acquisition occurs. First language forgetting is typically documented when speakers lose contact with their native language and are immersed in a second language speaking environment.

Although research has demonstrated that second language acquisition has possible effects on first language syntax (Altenberg, 1991; Liu, Bates, \& Li, 1992; Merino, 1983; Schaufeli, 1996: Schoenmakers-Klein, 1997; SilvaCorvalan, 1991), the most vulnerable area appears to be first language vocabulary (Ammerlaan, 1997; Hakuta \& D’ Andrea, 1992; Isurin, 2000; Klatter-Folmer, 1997; Kravin, 1992; Leopold, 1939; Leyen, 1984; Olshtain \& Barzilay, 1991; Soesma, 1997). For example, in Olshtain and Barzilay's study, both monolingual native English speakers and native English speakers who had immigrated to Israel and used Hebrew as their primary language were asked to describe a particular picture of a small body of water. The majority of the monolingual native English

This work was based on dissertation research conducted by L.I. submitted to Louisiana State University Interdisciplinary Linguistics Program, 1999. The research became possible thanks to the direction and supervision of J.M. Both authors contributed equally to this version of the work. We thank Jason Hicks, Claudius Kessler, Daniel Burns, and two anonymous reviewers for their comments on an earlier version of the manuscript. Correspondence should be addressed to J. L. McDonald, Department of Psychology, Louisiana State University, Baton Rouge, LA 70803 (e-mail: psmcdo@1su.edu). speakers used the word pond, but only a small portion of the Israeli Americans did. Rather, this group used various less appropriate but related words, such as swamp, puddle of water, water, riverbed, and so forth. Thus, they seemed to have lost access, at least temporarily, to the more specific or appropriate label for the picture.

First language forgetting has been predominately investigated by socio- and psycholinguists in individuals or groups of speakers who have experienced deterioration of their native language skills after extensive exposure to a second language environment. Although there is some empirical data on L1 forgetting, there is very little in the way of theoretical explanations of this phenomenon (de Bot, 1999; Pan \& Gleason, 1986). Researchers of L1 forgetting do not even agree as to whether $\mathrm{L} 1$ constructs are truly lost (Kravin, 1992; Leopold, 1939) or just temporarily inaccessible (Ammerlaan, 1997; Isurin, 2000; Leyen, 1984; Olshtain \& Barzilay, 1991).

In the present study, we attempted to simulate the process of L1 forgetting in a controlled laboratory setting by using a retroactive interference paradigm with foreign language vocabulary as stimuli. This permitted the exploration of the possible underlying causes of L1 forgetting. Retroactive interference (RI) is a well-established memory phenomenon in which new information interferes with the retrieval of old information. It is classically investigated in a task that requires subjects to learn material on a first list, then material on a second, or interpolated list; they are then tested on the material from the original list. Results typically show poorer recall of the first list as compared with a control condition in which no second list is given. In our study, vocabulary items were learned in one language on the first list, and then vocabulary items 
were learned in another language on the second list. Retesting the first list after the second list was learned yielded a measure of RI on first list vocabulary.

One factor known to effect RI is similarity between the original and the interpolated lists in terms of either content (e.g., Baddeley \& Dale, 1966; McGeoch \& McDonald, 1931) or process (Burns \& Gold, 1999). For example, there is more RI when the interpolated list includes synonyms of words on the first list rather than unrelated words; there is less RI when the interpolated list involves a different category of items from the first list-for example, numbers instead of words (McGeoch \& McDonald, 1931). Indeed, even for interpolated lists of synonyms of words from the first list, RI is a function of the degree of relatedness of the synonyms on the two lists $(\mathrm{McGeoch}$ $\&$ McDonald, 1931). RI is also found to occur when unrelated words from Lists 1 and 2 are processed similarly (i.e., under the same task instructions) and not to occur when they are processed differently (i.e., under different task instructions; Burns \& Gold, 1999).

The effect of similarity on RI is relevant to L1 forgetting. Although forgetting of L1 vocabulary could be due at least partly to lack of practice and to the length of time since a particular vocabulary item has been used, it is also possible that RI from second language translation equivalents is responsible for the inaccessibility of L1 items There is a high degree of similarity, or semantic overlap, between translation equivalents in the first and second language; this affects how bilinguals react to translation equivalents. For example, bilingual children acquiring two languages simultaneously often lose a word in one language when the translation equivalent is acquired in the other (Kravin, 1992; Leopold, 1939). Indeed, the degree of semantic similarity between translation equivalents appears to be stronger than that for within-language synonyms. For example, translation equivalents produce semantic priming and repetition priming for bilinguals (e.g., Altarriba, 1992; Altarriba \& Mathis, 1997; Altarriba \& Soltano, 1996); this effect is different than the pattern produced by within-language synonyms (e.g., Kanwisher $\&$ Potter, 1990). Given this high degree of semantic similarity, RI from second language translation equivalents on first language may be quite powerful.

Another factor known to influence the amount of RI is the amount of exposure to the interpolated list (Briggs, 1957; McGeoch, 1932; Melton \& Irwin, 1940; Underwood, 1945). Many studies have shown that increasing the amount of exposure to an interpolated list increases RI. Indeed, RI may be at a maximum when the amount of original learning and interpolated learning is approximately equal (Briggs, 1957; Melton \& Irwin, 1940; Slamecka, 1960). However, increased RI does not appear to be inevitable with increased exposure to the interpolated list. Recently, Bäuml (1996) has shown that there was not an increase in RI with increased exposure to the interpolated list if there was no recall of the interpolated list before the retest of the original list.
The degree of first language forgetting may also be a function of the amount of exposure to the second language (Mayor, 1992; Segalowitz, 1991). In studies of children, forgetting tended to increase with increased second language exposure (Isurin, 2000; Kaufman \& Aronof, 1991). For example, over the course of a year, Isurin tracked language changes in a Russian-speaking orphan who was adopted at the age of 9 by an American family with no knowledge of Russian. Thus, for this child, first language input was effectively ceased, and only second language input was received. Vocabulary knowledge in both the first and second languages was assessed periodically over the year by asking the child to name pictures in either Russian or English. The same set of pictures was named first in Russian, then in English. As can be seen in Figure 1, rapid acquisition of English vocabulary was accompanied by the child's gradual forgetting of Russian vocabulary.

Several other features of the performance of this Russian girl transplanted to the United States support an RI interpretation of her language forgetting. Difficulty in accessing particular Russian words appeared to occur after the English translation equivalent had been learned. For example, high-frequency words were acquired more easily in the second language than were low-frequency words. The high-frequency words also were subject to more forgetting and had slower access times than were the low-frequency words. In addition, cognates (words that have highly related surface forms across languages) appeared to be especially vulnerable to L1 forgetting. Due to their similarity to Russian items, English cognates appeared fairly easy for the girl to acquire. Once acquired, however, the English cognates appeared to cause problems for accessing the Russian equivalents, despite their phonological similarity. For example, she learned the English word flag (/flıg/ in Russian) about 7 months after her arrival in the United States. On five subsequent attempts, spread out over several months, the child either was not able to name flag in Russian or named it after an extremely long pause, whereas she successfully retrieved the item each time in English. Note also that the fact that L1 words were not totally lost, but could sometimes be accessed, is consonant with an RI explanation, rather than if the items had truly been lost (see also Ammerlaan, 1997; Hakuta \& D'Andrea, 1992).

\section{Breaking RI Down Into Gains and Losses}

Although traditionally RI is measured simply in terms of the overall decrease in recall between the first and second tests of first list items, recently Burns and Gold (1999) have suggested that RI can be broken down in terms of gains (items not recalled on the initial test, but recalled on the second test) and losses (items recalled on the initial test, but not on the second test). RI occurs when losses significantly exceed gains. Following the lead of literature on hypermnesia and the relational-item-specific processing account (Klein, Loftus, Kihlstrom, \& Aseron, 1989), gains have been proposed to be linked to increased 


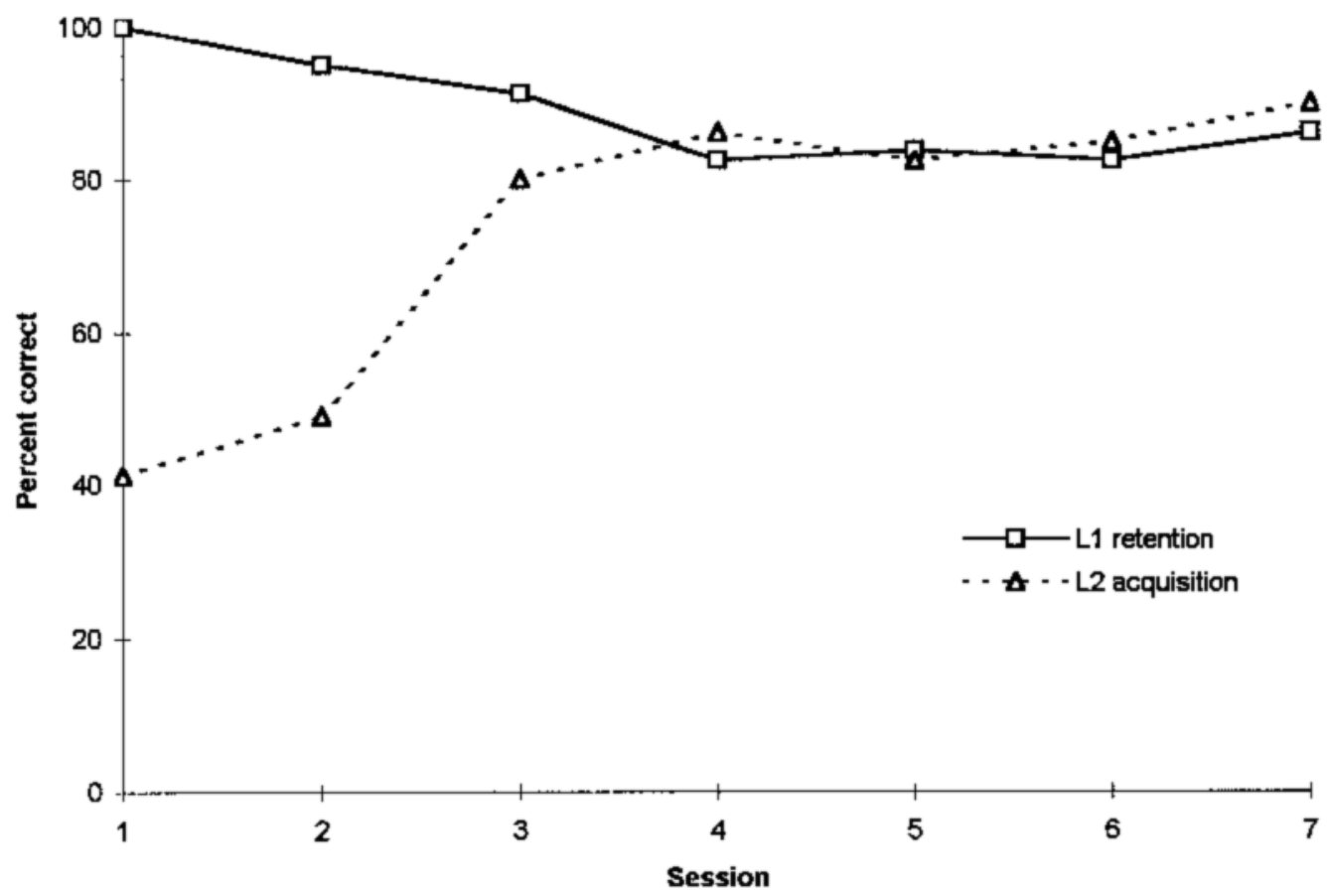

Figure 1. First language vocabulary loss and second language vocabulary acquisition over time for the case study. From “"Deserted Island' or a Child's First Language Loss" by L. Isurin, 2000, Bilingualism: Language \& Cognition, 3, p. 156. Copyright 2000 by Cambridge University Press. Adapted with permission.

item accessibility and losses to decreased item discriminability. Thus, if an interpolated task decreased accessibility in general, gains should be decreased. If an interpolated task decreased discriminability of items across lists, losses should increase. Both decreased gains and increased losses would contribute to increased RI.

Evidence that gains and losses in RI have different underlying causes was provided by Burns and Gold (1999) in a free-recall paradigm. They found that any intervening list, regardless of similarity to the original list, decreased gains as compared with when no interpolated list occurred. The authors related this effect to accessibility by noting that any interpolated list should decrease the accessibility of a first list compared with when there is no interpolated list, perhaps by adding to the number of potential items in the search space. Burns and Gold found that losses, on the other hand, were only affected when the intervening list was processed similarly to the original list. That is, losses were increased when an interpolated list was processed similarly to the original list; no such increase in losses was found when an interpolated list was processed differently. The authors tied this effect to discriminability, noting that the similarity of processing between the two lists would decrease item discriminability across lists.

Given the above review of the literature, we devised an experiment to test the effects of semantic similarity and amount of exposure to a second language on L1 forgetting. In addition to measuring how these factors affect RI, we also broke performance down into gains and losses, to see whether differences in accessibility or differences in discriminability were the responsible underlying mechanisms. In the experiment, the participants learned a first list containing 16 pictures and the corresponding foreign language words over 10 trials. (Foreign vocabulary items were used rather than true L1 items to control for the amount of exposure to the first list items.) A second list containing 16 pictures and words in a different foreign language consisted of either translation equivalents of the first list or totally different pictures and words. Amount of exposure to the second list was manipulated by having the participants go through the second list $2,5,10$, or 15 times. Tests were administered by showing a picture and asking for the appropriate foreign language word.

\section{METHOD}

\section{Participants}

The data set was derived from 112 undergraduate monolingual English-speaking students recruited from a participant pool in exchange for course extra credit. The majority of the participants had classroom foreign language experience (mostly Spanish or French); the participants with knowledge of Russian or Hebrew were excluded from the experiment. Fifty-seven participants who did not meet a preset learning criterion of producing a correct or closely related form for $80 \%$ of the words on the first list after the initial 10 study passes were replaced.

\section{Stimuli}

Lists of Russian and Hebrew words were used. These words corresponded to black-and-white line drawings of concrete objects and 
actions for the first study list. The first list consisted of either 16 words in Russian or the same words in Hebrew. The second list for the equivalents condition consisted of the same words in the other language. That is, if Russian vocabulary was presented on the first list, the same vocabulary was presented in Hebrew on the second list, and vice versa. The second list for the different condition consisted of 16 new words in the language different from those on the first list. That is, if Russian vocabulary was presented on the first list, new Hebrew vocabulary was presented; if Hebrew vocabulary was presented on the first list, new Russian vocabulary was presented. All words can be seen in the Appendix. Note that different items appeared on the Hebrew and Russian second lists in the different condition only so that all words could be easily pronounced by native English speakers. Drawings were pretested with native English speakers to be sure that they all elicited the desired concept. All concrete object drawings were of singular nouns; all actions were depicted being performed by a single person and thus elicited third person singular forms. Drawings were digitally scanned for presentation on a computer monitor.

The Russian names for each line drawing were digitally recorded by a native speaker. Similarly, the Hebrew names for the drawings were also digitally recorded by a fluent, though nonnative speaker of Hebrew; verb forms were presented in the masculine third person singular. Words in the two foreign languages were chosen so as to have no unusual phonemes for native English speakers. All words were either one or two syllables long.

\section{Procedure}

All participants were run individually in this study, with the time of the session varying between 45 and 65 min depending on the amount of exposure to the second list. After screening for foreign language experience, the participants were instructed that they were going to learn some vocabulary in a foreign language. They would see line drawings on the computer screen and hear the word portrayed in the line drawing in the foreign language over earphones. They were not informed about the nature of any possible later vocabulary test. Half the participants received Russian words on the first list, half received Hebrew.

There were 10 study passes through the first list. The first 2 passes involved familiarization with the vocabulary items, which were presented in a fixed random order. The participants saw a picture on the screen and heard, at a 1-sec delay, the foreign vocabulary item. They then had $2 \mathrm{sec}$ in which to repeat the new word aloud before the next picture was presented. The next 3 passes through the material were used for retrieval practice and had a different order of item presentation from the first 2 passes. The participants saw a picture on the screen and were given $3 \mathrm{sec}$ to try to say the correct foreign word aloud. Then the correct word was given, followed by a 4-sec interval, during which the participants were to repeat the word twice aloud. The last 5 passes involved further retrieval practice and had yet another different presentation order. The participants saw a picture, followed by a 4-sec delay, during which they were to attempt to say the correct word twice aloud. They then heard the correct word over the earphones and were given $4 \mathrm{sec}$ in which to repeat the word twice aloud. Thus, as exposure increased, more forced retrieval practice occurred, and the participant practiced articulating the word more often.

After the 10 passes through the first list, the participants received a test on the foreign vocabulary items. They were shown the pictures on the computer screen and asked to name them in the foreign language. If they could not recall the word, they were asked to give their best guess. During the test phase, the picture remained on the screen until an auditory response was picked up by the microphone. There was a 2-sec delay between response and the presentation of the next picture. The presentation order of the words in the test phase was different from the various study orders and remained the same for both the L1 test and the L1 retest.
After the completion of the test on the first list, the participants learned the second list, which was always in a different language from the first list. Half of the participants learned L1 translation equivalents in the new foreign language; the other half learned new vocabulary items. Crossed with this was the number of study passes through the second list that the participants received: One quarter had 2 study passes, one quarter had 5 study passes, one quarter had 10 study passes, and one quarter had 15 study passes. Characteristics of each study pass were the same as those for the first list. The additional study passes $11-15$ were identical in nature to passes $6-10$.

After studying the second list, the participants received a test of the second list items, followed immediately by the L1 retest. For the participants in the translation equivalents condition, order of items in the second list test was identical to that in the L1 tests. Both the second list test and L1 retest were administered in the same manner as the initial L1 test. The participants were never informed of the L1 retest, so this test came as a surprise to all participants. At the conclusion of the experiment, the participants were thanked for their participation, given a credit slip, and dismissed.

\section{Scoring and Analysis}

The participants were credited with correct recall of a foreign language word when their response was totally correct and when the response differed from the correct word in terms of only one phoneme, provided that the incorrect phoneme belonged to the same phonemic pair and differed only in terms of the voice/voiceless aspect (e.g., dovek instead of dofek [knock in Hebrew], or mozek instead of mozeg [pour in Hebrew] ). In addition, a response was considered correct if the participant had consistently mispronounced an item during study and gave the same mispronunciation during test. For example, there were a few typical words incorrectly learned and recalled by some participants, such as tratz instead of ratz (runs in Hebrew), vilkan instead of vilka (fork in Russian), boner instead of boneh (build in Hebrew), tol instead of pol (floor in Russian), or garder instead of gader (fence in Hebrew). These words remained in the same slightly incorrect form even after the correct word was heard through the earphones. If the word appeared in a form slightly different from the target one and was accepted as a correct response in the first $\mathrm{L} 1$ test, it had to be in the same form in the $\mathrm{L} 1$ retest to be accepted as correct. Any further deviation from the norm in the $\mathrm{L} 1$ retest would place the response in another category. These included related responses, within and across language errors as well as unrelated responses. Only results on correct responses are reported.

The design of the study was a 2 (overlap condition: translation equivalents or different items) $\times 4$ (exposure to the second list: 2,5 , 10 , or 15 passes) $\times 2$ (language order: Hebrew-Russian or RussianHebrew) $\times 2$ (test: initial first list test or first list retest) factorial design. The first three factors were between-subjects, and the last factor was a within-subjects variable. To investigate RI, an analysis of variance (ANOVA) of this design was run over both correct responses and latencies. Then RI was broken down into gains and losses, and 2 (overlap condition) $\times 4$ (exposure to the second list) $\times$ 2 (language order) ANOVAs were run on these dependent variables.

\section{RESULTS}

Before turning to the RI analyses, note that the experiment did successfully demonstrate loss of first list items with increasing second list exposure. Specifically, Figure 2 shows that L2 forgetting gradually increased with increasing exposure to the second list, whereas second list acquisition increased sharply with increasing exposure to the second list. The interaction between list (first vs. second) and amount of exposure to the second list was 


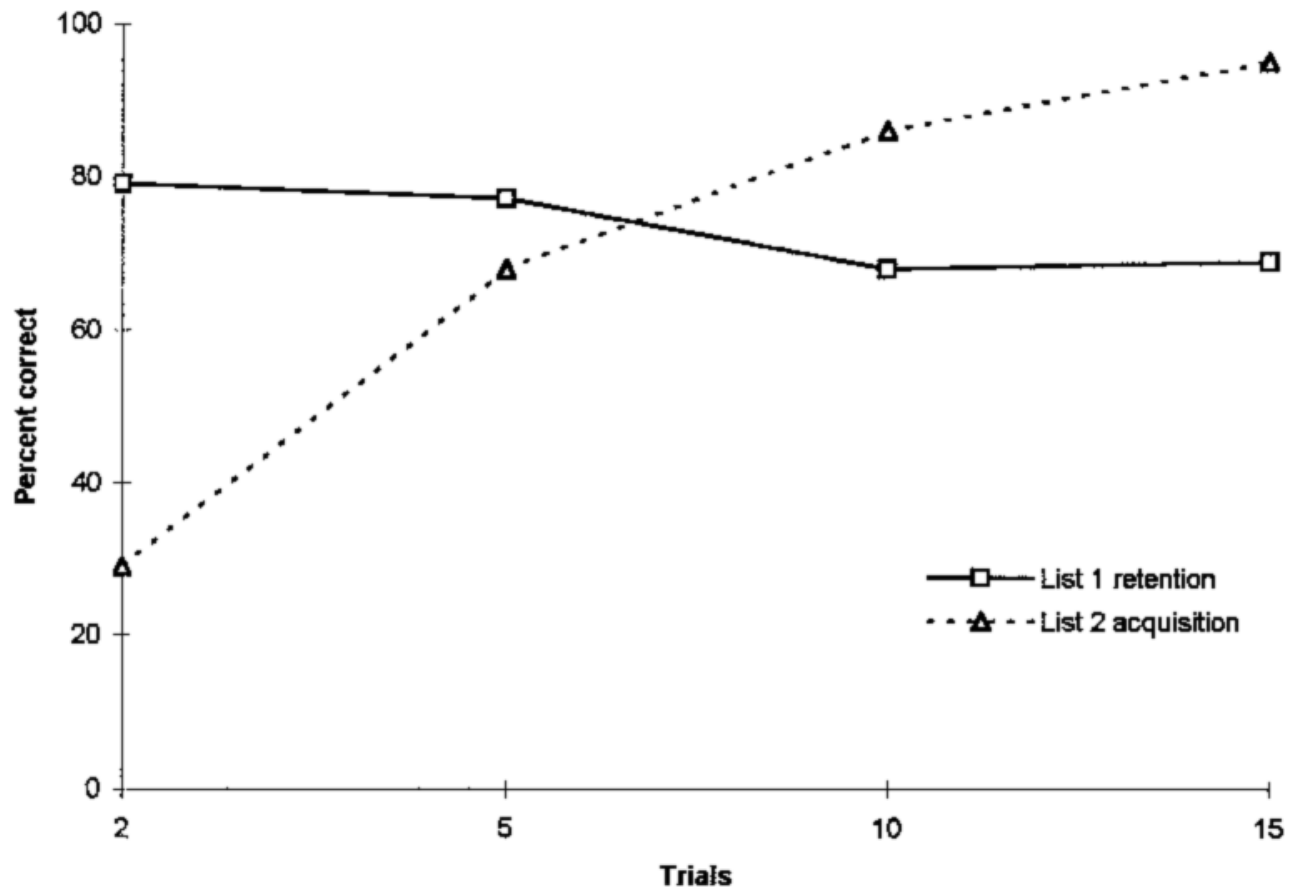

Figure 2. First list loss and second list acquisition over trials.

statistically significant $[F(3,96)=156.8, p<.001]$. Note that this curve is very similar to that given for the case study reported in the introduction (see Figure 1).

\section{RI Analysis on Responses}

The response analysis was performed on correct responses only; cell means are given in Table 1 . However, it should be noted that the same pattern of results as those detailed below occurred when a more liberal criterion was used and correct and related responses were analyzed together.

The repeated measures analysis revealed a significant main effect of test $[F(1,96)=63.3, p<.001]$ with better performance on the first test $(M=80.0 \%)$ than on the retest $(M=73.1 \%)$. In addition, there were several significant interactions involving the test factor; accordingly, separate analyses were done individually on each test occasion. Analysis of responses on the first test revealed a main effect only of language order, with the participants who learned Hebrew in this first phase $(M=83.3 \%)$ outperforming those who learned Russian first $(M=76.9 \%)$ $[F(1,96)=6.1, p<.05]$. Thus, the Hebrew words selected for this study were easier to learn than were the Russian words. However, collapsed across the first list language factor and before presentation of the interpolated list, all overlap conditions and second list exposure groups were equivalent.

Analysis of responses to the retest, which occurred after exposure to the interpolated list, yielded two main effects. The overlap condition was significant $[F(1,96)=4.2, p<$ $.05]$, with the participants who learned translation equiva- lents in the other language performing more poorly $(M=$ $70.0 \%)$ than those who learned the same items $(M=$ $76.2 \%$ ). Thus, as found by other researchers (Baddeley \& Dale, 1966; Burns \& Gold, 1999; McGeoch \& McDonald, 1931), similarity increased the amount of RI. The effect of amount of exposure to the second list was also significant $[F(3,96)=3.6, p<.05]$. A post hoc Tukey test revealed that recall for 10 exposures to the second language list $(M=67.2 \%)$ was significantly worse than that for 2 exposures to the list $(M=79.0 \%)$. Performance for 5 exposures $(M=77.0 \%)$ and 15 exposures $(M=69.2 \%)$ was intermediate and did not differ significantly from the other exposure groups. This result is similar to that found by Briggs (1957), who also noted that RI for recall appeared to be maximal when the amount of exposure to the second list was equal to that of the first list.

Specific influence of semantic overlap. The analysis above looked only for global effects of semantic overlap (i.e., that there is more forgetting in the overlap condition than in the different condition). However, the effect of semantic overlap should be specific. That is, learning of a List 2 translation equivalent should cause forgetting of that List 1 word and not a different List 1 word. This specific effect is what Isurin (2000) found in her case study of L1 forgetting. To test whether forgetting was specific to acquisition of a translation equivalent, we analyzed performance in the equivalents condition only. We compared two forgetting ratios: (1) the proportion of time an item was forgotten on the first list retest given that the item was correctly recalled on the original first list test and its translation equivalent correctly recalled on the second list test, 
Table 1

Performance on the RI Task

\begin{tabular}{|c|c|c|c|c|c|c|c|c|}
\hline \multirow{2}{*}{$\begin{array}{c}\text { Overlap } \\
\text { Condition }\end{array}$} & \multirow{2}{*}{$\begin{array}{c}\text { Amount of } \\
\text { List } 2 \text { Exposure }\end{array}$} & \multicolumn{2}{|c|}{$\%$ Correct } & \multicolumn{2}{|c|}{ Reaction Time } & \multirow[b]{2}{*}{ Gains } & \multirow[b]{2}{*}{ Losses } & \multirow{2}{*}{$\frac{\% \text { Correct }}{\text { List } 2}$} \\
\hline & & Test & Retest & Test & Retest & & & \\
\hline Different & 2 & 79.0 & 79.5 & 2,162 & 1,873 & 4.0 & 3.6 & 33.7 \\
\hline Different & 5 & 81.6 & 79.5 & 1,871 & 1,666 & 2.7 & 4.9 & 70.5 \\
\hline Different & 10 & 77.7 & 75.0 & 1,879 & 1,910 & 3.1 & 5.8 & 89.2 \\
\hline Different & 15 & 79.0 & 71.0 & 1,669 & 1,762 & 3.6 & 11.6 & 94.1 \\
\hline Equivalents & 2 & 83.5 & 78.6 & 1,806 & 1,664 & 2.2 & 7.1 & 23.6 \\
\hline Equivalents & 5 & 79.0 & 74.6 & 1,746 & 2,045 & 3.1 & 7.6 & 65.0 \\
\hline Equivalents & 10 & 78.6 & 59.4 & 1,640 & 2,754 & 1.8 & 21.0 & 83.4 \\
\hline Equivalents & 15 & 82.1 & 67.4 & 2,053 & 3,263 & 0.9 & 15.6 & 99.1 \\
\hline
\end{tabular}

Note-Reaction times measured in milliseconds.

and (2) the proportion of time an item was forgotten on the first list retest given that the item was originally correctly recalled on the original first list test, but its translation equivalent was not correctly recalled on the second list test. These data were analyzed in a 2 (forgetting ratio types above) $\times 4$ (number of trials) ANOVA. There was indeed a higher forgetting ratio when the translation equivalent was learned $(M=.18)$ than when it was not $(M=$ .09) $[F(1,52)=9.5, p<.005]$; this effect did not interact with trials. Thus, successfully acquiring a translation equivalent made it more likely that a participant would forget the same item on the first list; the effect of semantic similarity directly affected the item in question.

\section{RI Analysis on Reaction Times}

Only reaction times (RTs) for correct responses were analyzed. Table 1 gives the cell means. The repeated measures analysis of these RTs found a significant main effect of test $[F(1,96)=13.1, p<.001]$, with faster RTs on the first test $(M=1,853 \mathrm{msec})$ than on the retest $(M=$ $2,117 \mathrm{msec}$ ). In addition, there were several interactions involving the test factor, so again, separate analyses were performed on the two test occasions. Analysis of RTs on the first test showed no significant effects. Therefore, all groups were at equivalent starting positions.

Analysis of RTs on the retest showed the same main effects of overlap condition $[F(1,96)=21.7, p<.001]$ and amount of exposure $[F(3,96)=7.2, p<.001]$ as the response analysis, as well as a significant interaction between these two variables $[F(3,96)=7.2, p<.001]$. This interaction was further analyzed by a test of simple effects that showed that the translation equivalents condition was slower than the different condition only for the higher levels of List 2 exposure (10 and 15 trials). In addition, the amount of exposure had an effect only when translation equivalents intervened. For the translation equivalent conditions, times for 10 and 15 trials were significantly longer than those for 2 trials, and times for 15 trials were longer than those for 5 trials.

Summary of RI analyses. Both the response and the RT analyses show that similarity increases RI. This confirms prior work (Baddeley \& Dale, 1966; Burns \& Gold, 1999; McGeoch \& McDonald, 1931). Both dependent variables also showed effects of amount of exposure to the in- terpolated list, confirming previous results by many researchers (Briggs, 1957; McGeoch, 1932; Melton \& Irwin, 1940; Underwood, 1945). Note that this result does not contradict that of Bäuml (1996), since our study did involve retrieval of the second list-a situation in which Bäuml also found a relationship between amount of List 2 learning and RI.

\section{Gains}

Gains, shown in Table 1, were affected only by language order $[F(1,96)=4.8, p<.05]$. The participants whose original list was in Hebrew and intervening list was in Russian showed fewer gains $(M=1.8 \%)$ than those who originally learned Russian and had Hebrew as the intervening list $(M=3.6 \%)$.

Recall that on the original test of the first list, Hebrew had a higher performance than Russian, indicating that the Hebrew words were easier to learn than the Russian words. Thus, the participants who had Hebrew on the first list may have had less room to make gains, due to higher performance, than the participants who had Russian on the first list. Alternatively, learning more difficult words (i.e., Russian) on the second list may have decreased the accessibility of the words on the first list more than learning easier words (i.e., Hebrew) on the second list.

\section{Losses}

Losses, also shown in Table 1, were influenced by several significant factors. There was a main effect of overlap condition $[F(1,96)=16.0, p<.001]$ and a main effect of amount of exposure $[F(3,96)=7.9, p<.001]$. An interaction between overlap condition and amount of exposure $[F(3,96)=3.4, p<.05]$ qualified these main effects. A test of simple effects on this interaction showed that more losses occurred when translation equivalents intervened than when different items intervened only when the amount of exposure (trials $=10$ ) was the same for the first and second lists. Furthermore, the amount of exposure had an effect only when similar items intervened, with 10 trials differing from both 2 and 5 trials.

In addition, there was a marginal effect of language order $[F(1,96)=3.6, p<.07]$, with more losses for Hebrew-Russian learners $(M=11.2 \%)$ than for RussianHebrew learners $(M=8.1 \%)$. This was qualified by a sig- 
nificant interaction between amount of exposure and the language order $[F(3,96)=4.3, p<.01]$. The participants who learned Hebrew first showed an effect of amount of exposure ( 2 trials $M=3.6 \%, 5$ trials $M=5.8 \%, 10$ trials $M=16.1 \%, 15$ trials $M=19.2 \%$ ), whereas the participants who learned Russian first did not (2 trials $M=7.1 \%$, 5 trials $M=6.7 \%, 10$ trials $M=10.7 \%, 15$ trials $M=$ $8.0 \%)$. Languages showed a difference only at the highest amount of List 2 exposure (i.e., 15 trials). Thus, if the intervening words were harder or more effortful to learn, losses appeared to increase, especially with a lot of exposure to the difficult task.

Summary of gains and losses analysis. Similarity affected losses and not gains. Amount of exposure also affected losses and not gains. Thus, discriminability appears to be the mechanism underlying RI in the present experiment. In further support for the discriminability interpretation, amount of exposure had a significanteffect only when similar items intervened, and losses appeared to be at a maximum when List 1 and List 2 exposure were equivalent and therefore least discriminable.

\section{DISCUSSION}

More RI was caused by translation equivalents than by new concepts both in terms of fewer correct responses and slower RTs. Breaking RI down into gains and losses indicated that overlap condition affected losses only. It was hard to recall items from the first list when it was less discriminable from the second list, due to the high degree of semantic similarity between translation equivalents.

More RI was also found with increasing exposure to the interpolated list. This effect was caused by increased losses rather than by decreased gains. The increased losses with increased exposure were particularly strong when translation equivalents were used. Thus, increased List 2 exposure also affected discriminability, particularly for translation equivalents.

We did not find any evidence of a significant decrease in gains in the present experiment. Thus, there was no evidence that accessibility played a role in forgetting. However, several caveats must be mentioned before concluding that there is no effect of accessibility on L1 forgetting. First, in the present experiment, we used a cued rather than a free-recall test. The picture cue may have served to promote accessibility of the items and thus may have attenuated any differences in accessibility caused by the intervening lists. Second, in real-world L1 forgetting situations, a lot of time intervenes between the original learning of the first language and the forgetting. It may be that accessibility differences would be more evident at greater time delays or with even greater List 2 exposure.

A comment on the present paradigm is also in order in terms of broader research issues involving bilinguals. Use of an RI paradigm with translation equivalents may also serve to explore issues other than first language forgetting. For example, comparing the degree of interfer- ence caused by translation equivalents with that caused by within-language synonyms could shed light on how bilinguals store and process vocabulary in their two languages.

This study was undertaken to explore RI as a possible explanation for forgetting of L1 vocabulary after intensive exposure to a second language. RI was shown to be a strong factor in forgetting in circumstances that involved extremely high semantic overlap between items on two lists and when mastery of both lists was high. These circumstances are similar to those found in a typical L1 forgetting situation. Of course, the present experiment was a controlled laboratory study and not perfectly analogous to an L1 forgetting situation. Although the study looked at how previously learned vocabulary in a language was affected by later learned vocabulary in another language, the language in the first list was not the participants' native language, nor was it as highly learned as a native language would be. Nonetheless, the use of the controlled laboratory study has allowed us to support RI and, more specifically, discriminability as possible mechanisms of L1 forgetting. Further theoretical progress in understanding L1 forgetting should be possible through continued use of both naturalistic case studies and controlled laboratory studies.

\section{REFERENCES}

Altarriba, J. (1992). The representation of translation equivalents in bilingual memory. In R. J. Harris (Ed.), Cognitive processing in bilinguals (pp. 157-174). Amsterdam: Elsevier.

Altarriba, J., \& Mathis, K. M. (1997). Conceptual and lexical development in second language acquisition. Journal of Memory \& Language, 36, 550-568.

Altarriba, J., \& Soltano, E. G. (1996). Repetition blindness and bilingual memory: Token individuation for translation equivalents. Memory \& Cognition, 24, 700-711.

Altenberg, E. P. (1991). Assessing first language vulnerability to attrition. In H. W. Seliger \& R. M. Vago (Eds.), First language attrition (pp. 189-207). Cambridge: Cambridge University Press.

Ammerlaan, T. (1997). 'Corrosion' or 'loss' of immigrant Dutch in Australia: An experiment on first language attrition. In J. KlatterFolmer \& S. Kroon (Eds.), Dutch overseas (pp. 69-97). Tilburg: Tilburg University Press.

Baddeley A. D., \& Dale, H. A. (1966). The effect of semantic similarity on retroactive interference in long- and short-term memory. Journal of Verbal Learning \& Verbal Behavior, 5, 417-421.

BäUML, K.-H. (1996). Revisiting an old issue: Retroactive interference as a function of the degree of original and interpolated learning. Psychonomic Bulletin \& Review, 3, 380-384.

BRIGGS, G. (1957). Retroactive inhibition as a function of the degree of original and interpolated learning. Journal of Experimental Psychology, 53, 60-67.

Burns, D. J., \& Gold, D. E. (1999). An analysis of item gains and losses in retroactive interference. Journal of Experimental Psychology: Learning, Memory, \& Cognition, 25, 978-985.

DE Bot, K. (1999). The psycholinguistics of language loss. In G. Extra \& L. Verhoeven (Eds.), Studies on language acquisition (pp. 345361). Berlin: Walter de Gruyter.

Hakuta, K., \& D' Andrea, D. (1992). Some properties of bilingual maintenance and loss in Mexican background high-school students. Applied Linguistics, 13, 72-99.

IsURIN, L. (2000). "Deserted island" or a child's first language loss. Bilingualism: Language \& Cognition, 3, 151-166. 
Kanwisher, N., \& Potter, M. C. (1990). Repetition blindness: Levels of processing. Journal of Experimental Psychology: Human Perception \& Performance, 16, 30-47.

Kaufman, D., \& Aronof, M. (1991). Morphologicaldisintegration and reconstruction in first language attrition. In H. W. Seliger \& R. M. Vago (Eds.), First language attrition (pp. 175-189). Cambridge: Cambridge University Press.

KLATTER-Folmer,J. (1997) Language shift and loss in a three-generation Dutch family in New Zealand. In J. Klatter-Folmer \& S. Kroon (Eds.), Dutch overseas (pp. 195-214). Tilburg: Tilburg University Press.

Klein, S. B., Loftus, J., Kinlstrom, J. F., \& Aseron, R. (1989). Effects of item-specific and relational information on hypermnesic recall. Journal of Experimental Psychology: Learning, Memory, \& Cognition, 15, 1192-1197.

Kravin, H. (1992). Erosion of a language in bilingual development. Journal of Multilingual \& Multicultural Development, 13, 307-325.

LEOPOLD, W. R. (1939). Speech development of a bilingual child: A linguist's record. Vol. 1: Vocabulary growth in the first two years. Chicago: Northwestern University Press.

LEYEN, I. A. (1984). Native language attrition: A study of vocabulary decline. Dissertation Abstracts International, 46(9), 2602.

Liu, H., BATES, E., \& LI, P. (1992). Sentence interpretation in bilingual speakers of English and Chinese. Applied Psycholinguistics, 13, 451484.

MAYOR, R. C. (1992). Losing English as a first language. Modern Language Journal, 76, 190-209.

МсGеосн, J. A. (1932). The influence of degree of interpolated learning upon retroactive inhibition. American Journal of Psychology, 44, 695-708

McGeoch, J. A., \& McDonald, W. T. (1931). Meaningful relation and retroactive inhibition. American Journal of Psychology, 43, 579-588.

Melton, A. W., \& Irwin, J. M. (1940). The influence of degree of interpolated learning on retroactive inhibition and the overt transfer of specif ic responses. American Journal of Psychology, 53, 173203.

Merino, B. J. (1983). Language loss in bilingual Chicano children. Journal of Applied Developmental Psychology, 4, 277-294.

Olshtain, E., \& Barzilay, M. (1991). Lexical retrieval difficulties in adult language attrition. In H. W. Seliger \& R. M. Vago (Eds.), First language attrition (pp. 139-151). Cambridge: Cambridge University Press.

Pan, B. A., \& Gleason, J. B. (1986). The study of language loss: Models and hypotheses for an emerging discipline. Applied Psycholinguistics, 7, 193-206.

Schaufeli, A. (1996). Word order patterns in contact: Turkish in the Netherlands. Southwest Journal of Linguistics, 15, 153-169.

SchoenmaKers-Klein, G. (1997). Dutch language loss in Brazil and the conceptual hypothesis. In J. Klatter-Folmer \& S. Kroon (Eds.), Dutch overseas (pp. 99-119). Tilburg: Tilburg University Press.

Segalowitz, N. (1991). Does advanced skill in a second language reduce automaticity in the first language? Language Learning, 41, 5983.

Seliger, H. W., \& VAgo, R. M. (Eds.) (1991). First language attrition. Cambridge: Cambridge University Press.

Silva-Corvalan,C. (1991). Spanish language attrition in a contact situation with English. In H. W. Seliger \& R. M. Vago (Eds.), First language attrition (pp. 151-171). Cambridge: Cambridge University Press.

Slamecka, N. J. (1960). Retroactive inhibition of connected discourse as a function of practice level. Journal of Experimental Psychology, 59, 104-108.

Soesma, A. (1997). An experimental study on native language attrition in Dutch adult immigrants in Israel. In J. Klatter-Folmer \& S. Kroon (Eds.), Dutch overseas (pp. 181-194). Tilburg: Tilburg University Press

UNDERWOOD, B. J. (1945). The effect of successive interpolations on retroactive and proactive inhibition. Psychological Monographs, 59(3, Whole No. 273).

APPENDIX

\begin{tabular}{|c|c|c|c|}
\hline \multicolumn{4}{|c|}{ Stimuli Translation Equivalents Condition } \\
\hline Russian & & & Hebrew \\
\hline palto & & & me'il \\
\hline zabor & & & gader \\
\hline vilka & & & mazleg \\
\hline pol & & & ritzpa \\
\hline voda & & & ma'im \\
\hline stakan & & & kos \\
\hline hleb & & & lehem \\
\hline shar & & & kadur \\
\hline vidit & & & ro'eh \\
\hline sh'et & & & tofer \\
\hline spit & & & jashen \\
\hline svistit & & & shorek \\
\hline stro'it & & & boneh \\
\hline stuchit & & & dofek \\
\hline l'jet & & & mozeg \\
\hline bezit & & & ratz \\
\hline \multicolumn{4}{|c|}{ Stimuli in Different Condition } \\
\hline Russian & English & Hebrew & English \\
\hline gorka & slide & motos & airplane \\
\hline metla & broom & kufsa & box \\
\hline korol & king & kluv & cage \\
\hline list & leaf & hatul & cat \\
\hline lev & lion & pil & elephant \\
\hline sova & owl & sakin & knife \\
\hline grusha & pear & ele & leaf \\
\hline kit & whale & kesef & money \\
\hline est & eat & ohel & eat \\
\hline du'jet & blow & nose & carry \\
\hline neset & carry & tofes & catch \\
\hline plachet & cry & bohe & cry \\
\hline letit & fly & roked & dance \\
\hline gladit & iron & af & fly \\
\hline pilit & saw & shotel & plant \\
\hline mo'jet & wash & kore & read \\
\hline
\end{tabular}

(Manuscript received February 16, 2000; revision accepted for publication July 10, 2000.) 